\title{
Our Surgical Heritage: Great Scots of Anatomy and Surgery
}

\author{
Rao R Ivatury
}

\author{
Abstract \\ Background: The Royal College of Surgeons of Edinburgh, established in 1505 as the Barber Surgeons of Edinburgh was one of the oldest \\ medical organizations in the world. \\ Materials and methods: Literature review of the history of great Scottish surgeons of the 18th and 19th centuries and their accomplishments. \\ Conclusion: Edinburgh and Scotland in the 18th and 19th centuries were renowned for their cutting-edge medicine and surgery. \\ Clinical significance: A history of our surgical heritage. \\ Keywords: Historical review, Royal College of Surgeons of Edinburgh, Scottish anatomists and surgeons, Surgeons' Hall museums. \\ Panamerican Journal of Trauma, Critical Care \& Emergency Surgery (2021): 10.5005/jp-journals-10030-1315
}

\section{INTRODUCTION}

The author was invited to deliver the 2018 annual "Sir Astley Cooper Lecture" by the British Hernia Society in Edinburgh, Scotland. The topic was "reflections on the open abdomen". The preparation for this occasion recalled that open abdomen was an original contribution by a great surgeon of Scottish origin, Sir Heneage Ogilvie. ${ }^{1,2}$ The chance to learn about pioneer Scottish Surgeons and their remarkable contributions to the evolution of modern science led to further research. The visits to the Royal Infirmary and the Surgeons' Hall museums ${ }^{3}$ were awe-inspiring as was the history of Scottish surgery.

A product of this experience, this report reviews the pioneering contributions of these great Scots to our specialty of emergency surgery and critical care. It aims to stimulate a thirst for history in young surgeons. Constraints of space will focus this communication on selected, eminent Scottish surgeons from the 18th and 19th centuries.

\section{Rise of Scottish Medical Institutions ${ }^{4}$}

The Faculty of Physicians and Surgeons of Glasgow (1599) and the Royal College of Physicians of Edinburgh (1681) were established in the early modern period. In the 18th century, the University of Edinburgh Medical School, together with the Royal Infirmary (established in 1729), was responsible for the systematic teaching of medicine. King George III, in 1778, granted a new charter giving the surgeons' corporation the title "The Royal College of Surgeons of the City of Edinburgh". These august establishments would produce some of the greatest Scottish doctors. Scottish medicine rose up to its peak as the world leader.

\section{Medical Dynasties of Scotland}

Scotland had many medical dynasties in the late seventeenth and early eighteenth centuries. The Monros ${ }^{5-9}$ and the Bells $s^{10-12}$ lead the list. The Monros chaired the Department of Anatomy at the Edinburgh University for a collective 120 years starting from 1720. Successive generations of Bells became the Presidents of the Royal College of Surgeons, Edinburgh.

\section{Alexander Monro Primus (1697-1767)}

Surgeon and anatomist, Alexander Monro Primus (Fig. 1), was born in London and attended the University of Edinburgh from 1710 to
Department of Surgery, Virginia Commonwealth University, Richmond, Virginia, USA

Corresponding Author: Rao R Ivatury, Department of Surgery, Virginia Commonwealth University, Richmond, Virginia, USA, Phone: +1 804 6511575, email: raoivatury@gmail.com

How to cite this article: Ivatury RR. Our Surgical Heritage: Great Scots of Anatomy and Surgery. Panam J Trauma Crit Care Emerg Surg 2021;10(1):8-15.

Source of support: Nil

Conflict of interest: None

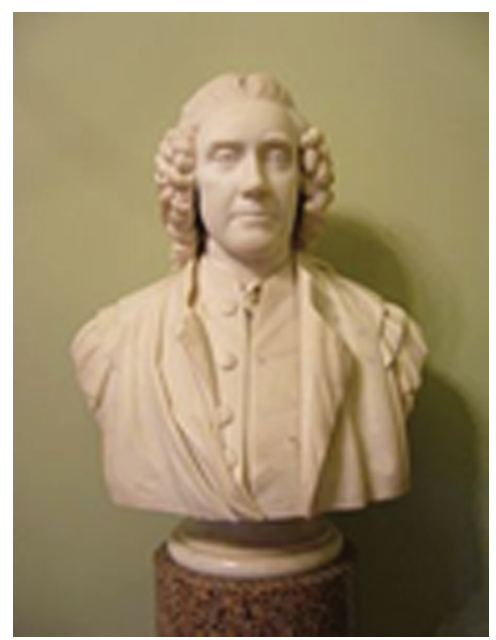

Fig. 1: Alexander Monro Primus

1713 where he became proficient in languages (Greek, Latin, and French), natural philosophy, and mathematics. He was a student of anatomy under the renowned William Cheselden and the great Herman Boerhaave. He was appointed University Chair of Anatomy in 1720, even though critics blamed it on nepotism from his father. ${ }^{6}$ In 1726, Monro published his magnum opus, The Anatomy of the Human Bones. Even without any illustrations, it was so popular that it went for seven editions. In 1729, he rented a house with six beds for taking care of the sick poor. Here, he taught students 


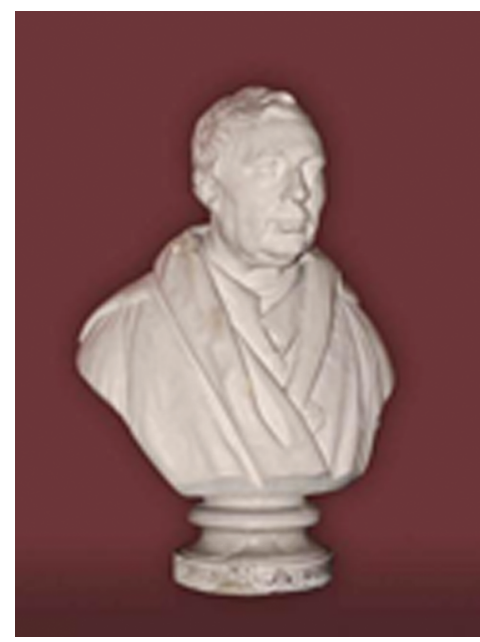

Fig. 2: Alexander Monro Secundus

anatomy and lectured using wax models. This house formed the roots of the Edinburgh Infirmary! A philanthropist and a man with great personal magnetism, he died from rectal cancer in 1767. Monro's other major contributions were founding the Society for the Improvement of Medical Knowledge (forerunner of the Royal Society of Edinburgh) and "Medical Essays and Observations", regarded as the first regular medical journal in Britain; one of the first in the world, and the first journal to introduce peer review.,

\section{Alexander Monro Secundus ${ }^{9}$ (1733-1817)}

Monro Secundus (Fig. 2) was the second and most accomplished Monro. He was born in Edinburgh. In 1753, at the age of 20, he was precociously named joint Professor of Medicine and Anatomy! He studied anatomy first in London under William Hunter and then with the German legend, Johann Meckel in Leiden. He took over his father's class and full duties of the professorship in 1758 . He became a Fellow of the Royal College of Physicians of Edinburgh in 1759 and served as President from 1779 to 1782 . He taught at Edinburgh University for 50 years and was the most influential anatomy professor in the English-speaking world. In 1764, he described his discovery of a foramen (foramen of Monro) between the lateral ventricles and the third ventricle but did not publish this till 1783. Two of his most successful books were "Observations on the Structure and Function of the Nervous System" and "Three Treatises on the Brain, the Eye, and the Ear". In 1783, he established his doctrine that came to be called the Monroe-Kellie Doctrine. (It was confirmed by his former student Kellie 40 years later.)

Monro was a friendly, gregarious but argumentative man. He had an attack of apoplexy in 1813 and died in 1817.

\section{The Bells: Benjamin Bell (1749-1806), Father of Edinburgh School of Surgery}

The next famous dynasty of Scotland was the Bells. ${ }^{10-12}$ Benjamin Bell (Fig. 3) was born in Dumfries on September 6, 1749, and studied medicine at Edinburgh University. His mentors were the distinguished Alexander Monro secundus, John Hunter and Percivall Pott. At the age of 24, he was elected one of four attendant surgeons to the Royal Infirmary of Edinburgh, where he would remain for 18 years. A fall from horseback in 1775 lead to a hiatus in surgical practice but gave him the time to write and reflect. Later, he went into practice in Edinburgh with two distinguished surgeons and established a huge practice. In 1783, he was one of

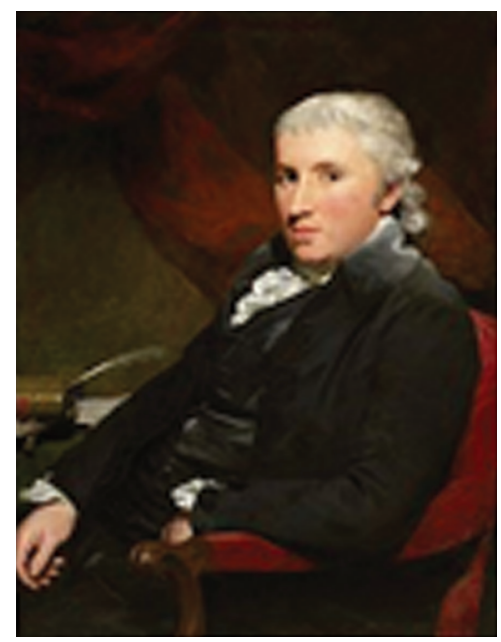

Fig. 3: Benjamin Bell

the founding Fellows of the Royal Society of Edinburgh. His treatise on venereal disease was one of the early works that suggested syphilis and gonorrhea were different diseases. ${ }^{11}$ Bell's main contribution to surgical practice was his emphasis on saving skin and on routine pain relief in surgery. He was well known for his six-volume textbook, A System of Surgery that went on to seven editions in multiple languages. ${ }^{10}$

\section{Dynasty}

The Bell dynasty includes Benjamin Bell's sons George Bell (17771832), Robert Bell (1782-1861), and William Bell (1783-1849), all surgeons and Fellows of the Royal College. Another son, Joseph, grandson Benjamin and great-grandson Joseph (1837-1911), all surgeons in Edinburgh, became presidents of the Royal College of Surgeons of Edinburgh. His great-grandson Joseph Bell (1837-1911) was known for his diagnostic acumen, and for his powers of observation. ${ }^{10,11}$

\section{Curious Anecdote}

There was a young medical student by the name of Arthur Conan Doyle, who was keenly impressed by Joseph Bell. Doyle created the fictional detective Sherlock Holmes, fashioned after Bell. ${ }^{10,11} \mathrm{~A}$ letter written in 1892 by Doyle to Bell and displayed at the Surgeons' Hall Museums ${ }^{3}$ in Edinburgh makes the influence clear: "It is most certainly to you that I owe Sherlock Holmes". Also at the museum was this note as Doyle recounted the creation of Holmes. "I thought of my old teacher Joe Bell, of his eagle face, of his curious ways, of his eerie trick of spotting details".

\section{John Hunter (1728-1793) "Father of Modern Scientific Surgery"13-15}

John Hunter (Fig. 4), one of the most distinguished scientists and surgeons of his day, was born in 1728. Even though he was an indifferent student, he had the good fortune of support from his elder brother William, who allowed him to assist with dissections in his anatomy school. He soon became an expert in anatomy and built up a collection of specimens, nearly 14,000 of skeletons and organs of animals.

Hunter studied under William Cheselden at Chelsea Hospital and Percival Pott at St. Bartholomew's Hospital. After a career in the army, he set up his own anatomy school in London in 1764 and his private surgical practice in 1776 . His surgical practice could not 


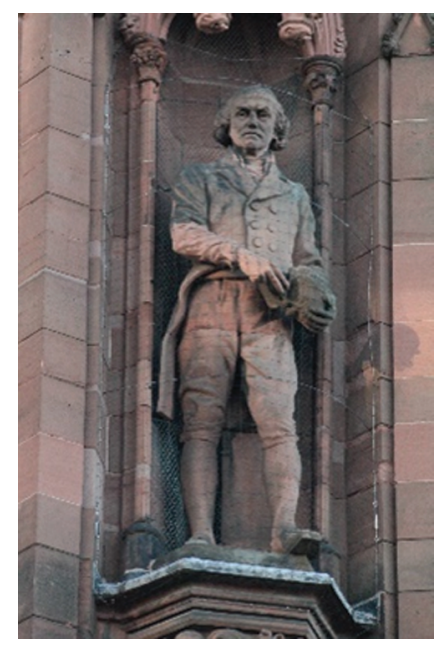

Fig. 4: John Hunter

support his passion for anatomic dissection. Like other anatomists of the era, he engaged grave robbers for his supply of cadavers. In 1783, Hunter moved to a large house in Leicester Square to establish a teaching museum with his large collection of thousands of specimens of plants and animals. One prominent piece was the skeleton of the $2.31 \mathrm{~m}\left(7^{\prime} 7^{\prime \prime}\right)$ Irish giant Charles Byrne. Hunter defied Byrne's last wish on his death bed to be buried at sea. Bribing a member of the funeral party, he obtained the skeleton and even published a scientific description of the anatomy. ${ }^{13,14}$

Hunter was elected a Fellow of the Royal Society in 1767 and was appointed as surgeon to St George's Hospital in 1768. In March 1790, he was made surgeon general by Prime Minister, William Pitt. While in this post, he instituted a reform of the system for appointment and promotion of army surgeons based on experience and merit, rather than the patronage-based system that had been in place.

Hunter was the first to advocate a scientific approach to disease. He researched blood while bloodletting patients with various diseases. He advanced the concept of inflammation as the body's response to disease. Nothing with regard to human anatomy escaped his attention. He described placental circulation and the development of the fetus, bone growth and remodeling, inflammation, the pathology of gunshot wounds, venereal disease, and malformations of the heart. His research focused on infectious processes, inflammation from gunshot wounds, cancer of the breast and rectum. Hunter created experiments to test his concepts, maintaining it is better to experiment than to ask theoretical questions. ${ }^{13-15}$

As a teacher, Hunter lacked brilliance. ${ }^{15}$ Still, an estimated 1,000 young surgeons were his students and it is no surprise that Hunter had many distinguished pupils such as John Abernathy, Henry Cline, Astley Cooper, and from America William Shippen. Hunter's unique collection of $>3,000$ animals, live and preserved, were maintained in a property called Earl's court outside London and were used for scientific studies. There were gifts from Queen Victoria (a bull) and rare specimens from Captain Cook and his explorations, including a skull of a kangaroo. ${ }^{15}$

Hunter was kindly and generous but readily provoked. He has suffered angina pectoris since the age of 45 . His eminence and accomplishments were a source of jealousy to his colleagues at St George's hospital, who tried to sabotage him. In 1793, at the age of 65 , in a meeting for the admission of prospective students under

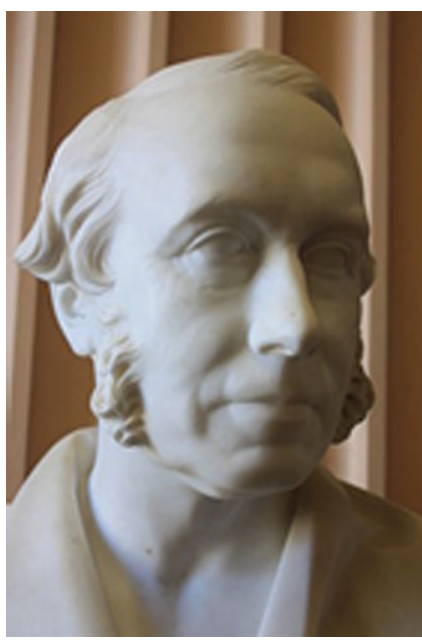

Fig. 5: James Syme

new regulations, Hunter furiously supported two of his applicants, lost his temper, collapsed, and died. ${ }^{14,15}$

The evil deeds of Home, Hunter's brother-in-law, and partner nearly annihilated the Hunterian documents and research papers. "The story of Home and the destruction of Hunter's priceless manuscripts, papers, and correspondence is a story equally compelling as the fictions of Drs. Doolittle and Jekyll and Mr. Hyde". ${ }^{15}$ Hunter never cared for Home as he did for his favorite student, Clint, who was brilliant and devoted. The saga of Clint's rescue of this treasure is nicely summarized by Kelly and Talboy. ${ }^{15}$

\section{An Interesting Tale}

Home's shenanigans left the Hunter family in financial ruin, who could not afford Hunter's burial in a place of honor as the Westminster Abbey that he richly deserved. Instead, his remains were interred at St. Martin's-in-the-Fields in an unmarked grave, since memorial plaques were prohibited by rules at that site. In 1859, the coffins at the church were moved for reinterment. Kelly and Talboy ${ }^{15}$ give us this fascinating account: "Francis Buckland, a surgeon and naturalist like Hunter, took the task of locating Hunter's remains among the 3,060 in St. Martin's church. After 16 days of searching, he found it. There were only three left to examine". The remains were then moved to a place of honor in the north aisle of the Abbey.

\section{Curious Fact}

Hunter was one of only two surgeons in the United Kingdom who have a public monument. Hunter's statue stands in Leicester Square. ${ }^{14}$

\section{James Syme, the Napoleon of Surgery (1799-1870) ${ }^{16-21}$}

An author of several surgical books, manuals, and numerous articles, James Syme (Fig. 5) was one of the great surgeons and teachers. James Syme took over anatomy class from his distant cousin and later rival and competitor, Robert Liston. He spent some time studying in Paris with Dupuytren, and Lisfranc. On his return to Scotland, he became a Fellow of the Royal College of Surgeons and in 1833 he became a Clinical Professor of Surgery at the University of Edinburgh. In his 36 years in this position, his surgical service became the mecca of surgery in Scotland. He had, to his credit, a wide array of surgical procedures, including amputation at the 
hip joint, excision of a jaw tumor, perineal approach to relieving urethral obstruction, operations for femur fracture, arthritis of the elbow, obstruction and aneurysm of blood vessels, cancer of the tongue, urological and rectal problems and, of course, the Syme's amputation at the ankle. ${ }^{21}$ Other innovative actions of Syme's included support of antisepsis (introduced by his son-in-law, Joseph Lister), ${ }^{21}$ chloroform anesthesia and reforms into medical education. In 1862, he was made surgeon in ordinary to the Queen in Scotland, received the French Légion d'honneur, a Danish knighthood, and later, several other orders in Britain and continental Europe.

\section{Curious Anecdote}

The Mackintosh, the famous raincoat that affords total protection from the heaviest rain was actually invented by Syme as a young man by impregnating it with a coal tar derivative. Syme never applied for a patent for the invention. ${ }^{18}$

\section{Joseph Lister ("Father of Modern Surgery") 22-27}

Joseph Lister (Fig. 6), following Louis Pasteur's advances in microbiology, championed the use of carbolic acid as the first antiseptic to become widely used in surgery that led to a reduction in postoperative infections. ${ }^{22-27}$

After graduating with honors from medical school, Lister joined the Royal College of Surgeons at the age of 26. In 1854, he became the first assistant to surgeon James Syme at the University of Edinburgh and Edinburgh Royal Infirmary. He married Syme's daughter, Agnes, and they spent their honeymoon visiting leading medical institutions in France and Germany. Agnes became a lifelong partner in Lister's laboratory. ${ }^{26}$ Lister was a professor of surgery at the University of Glasgow when he studied the papers of Pasteur on the elimination of microorganisms by filtration, exposure to heat, or exposure to solution/chemical solutions. Lister confirmed Pasteur's conclusions with his own experiments and focused on the idea of the chemical. He came across carbolic acid, which was known in the shipping industry to prevent rotting of industry wood. Trying it on wounds, he found that the solution reduced the incidence of gangrene. He recommended that surgeons should wear clean gloves and wash their hands before and after operations with $5 \%$ carbolic acid solution and to wash instruments and spray the operation theater with the solution. His ideas, however, were mocked. Carbolic acid was disliked because of irritation to the eyes and breathing. Lister's germ theory was too new to become

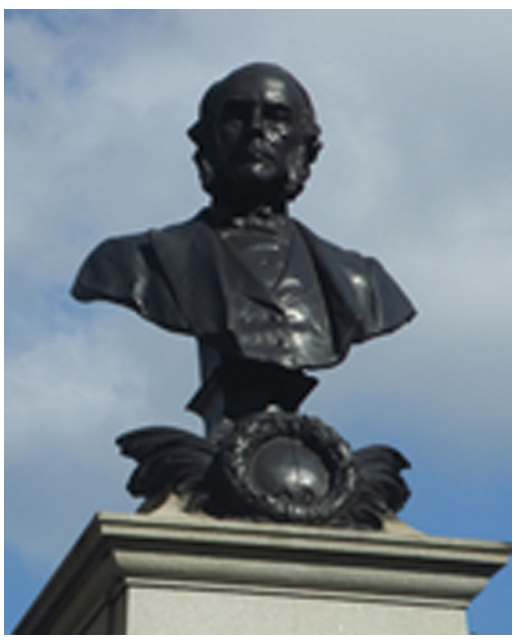

Fig. 6: Joseph Lister popular and his laborious and unattractive writing style did not help his cause either. Prestigious medical journals like Lancet warned against the theory. ${ }^{22-25}$

Lister left Glasgow University in 1869 and returned to Edinburgh as successor to Syme as Professor of Surgery at the University of Edinburgh. His contributions included surgical techniques of mastectomy and repair of the patella with wire. He was the first surgeon to use catgut ligatures, sutures, rubber drains, and an aortic tourniquet. He was a consultant to King Edward VII, during his illness with appendicitis 2 days before his coronation. The King was grateful for his advice on the latest antiseptic surgical methods.

Lister was president of the Royal Society between 1895 and 1900. He received Baronetcy in 1883 and 1897. He also received one of Prussia's highest orders of merit and in 1889 he was elected as a Foreign Member of the Royal Swedish Academy of Sciences. Following his death, a memorial fund led to the founding of a prestigious prize, the Lister Medal, many medical buildings and educational institutes in Glasgow and London were named after Lister. The highest point in the Royal Society Range, Antarctica was named Mount Lister. The father of surgery died on February 10, 1912, at his country home in Walmer, Kent at the age of 84 .

\section{Curious Facts}

Lister was the second surgeon to have a public monument in the United Kingdom. A statue of Lister stands in Kelvingrove Park, Glasgow. Lister is unique in having dedicated plaques at both King's College and University College, London. ${ }^{27}$

\section{William Macewen (1848-1924), a Father of Neurosurgery ${ }^{28-34}$}

A disciple and a true follower of Lister, William Macewen (Fig. 7) was born on June 22, 1848, on the Isle of Bute. Macewen obtained his medical degree in 1872 from the University of Glasgow. As a student Macewen attended Joseph Lister's lectures on the "Principles and Practice of Surgery" and Lister made a profound impression on him. Macewen's first published article, in 1869, described a "Blood Transfusion Carried Out by Mr Lister" ${ }^{\prime 30}$ and the two exchanged correspondence throughout the remainder of their lives. Macewen practiced Listerian principles of antiseptic surgery and introduced the sterilizable surgical gown.

Macewen had a "Hunterian" personality, questioning current opinions or views and not accepting them till tested by experiment

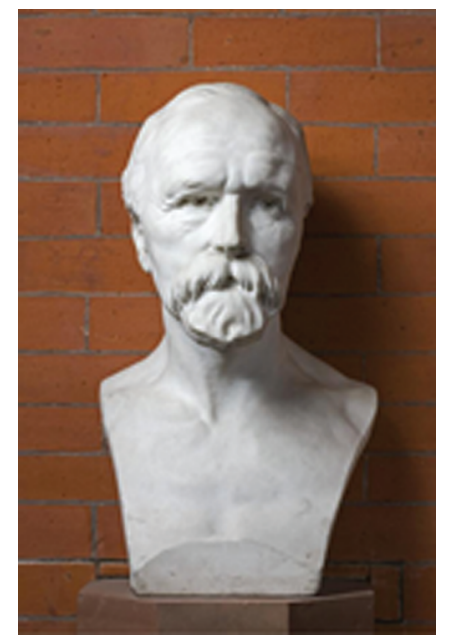

Fig. 7: William Macewen 
or experience. ${ }^{30}$ With a passion for surgery, he rose to the position of full surgeon and a lecturer at the Royal Infirmary School of Medicine. He was a master clinician and a slow and deliberate surgeon, devoted to scrupulous care and constant vigilance. With a tall, commanding figure, the royal "we" came to him often and naturally. An individualist, he once expressed, when organizing a scheme for the treatment of the limbless: "I'll take it up on one condition, that you do not ask other surgeons to co-operate; I am not a co-operator". ${ }^{29,30}$ The University of Glasgow made him the Regius Professor of Surgery in 1892. Cano ${ }^{29}$ gives a fascinating account of Macewen's personality.

Macewen pioneered the creative use of photographs for documenting patient cases and for teaching surgery and medicine. ${ }^{31}$ He would use photos of body parts and pathological specimens, as well as pre- and postoperative photographs. They came to be known as the Private Journals (PJs) of Dr Macewen. Summerly's delightful thesis on the subject of clinical photography of the 19th century provides an invaluable and fascinating insight into Macewen's surgical and photographic abilities. ${ }^{31}$ There were originally at least fifteen volumes of Macewen's collection of clinical photographs developed over a period of 30 years or so and contained over 800 items.

One of the first entries in Volume I of the PJs illustrates the amazing clinical skill of Macewen. JM was admitted to the Infirmary on July 21,1876 , suffering from an abscess on the brain. His parents, however, refused to allow Macewen to operate. He died 36 hours later. With parents' permission the skull was trephined, the brain exposed, and an instrument was introduced into the frontal convolution, revealing an abscess the size of a pigeon's egg. The location of the abscess was precisely where Macewen predicted premortem. JD was another example. He was admitted on March 13,1879 , suffering from swelling on the right side of his face and brow. Macewen decided to operate when the patient's condition got worse. An incision was made to expose a depressed fracture of the skull. Macewen elevated this portion by trephining. The patient recovered well. Another example of a brilliant clinical examination, localization of the tumor, and pioneering surgery relates to a tumor of the dura mater in 1879 . The patient, a teenage girl, lived for eight more years, and a subsequent autopsy showed no trace of the tumor. Macewen had a record of 24 cases of cerebral abscess operated on with 23 recoveries! This in the days without radiographs or scans!

In 1893, Macewen published his book "Pyogenic Disease of the Brain and Spinal Cord", a detailed account of 93 intracranial infective cases, a far cry from the occasional case report prevalent at that time. ${ }^{32} \mathrm{~A}$ companion volume, authored by him alone, was entitled "Atlas of Head Sections: Fifty-Three Engraved Copperplates of Frozen Sections of Head, and Fifty-Three Key Plates with Descriptive Texts". "The Surgeon", wrote Macewen in his preface, "'who is about to perform an operation on the brain has in these cephalic sections a means of refreshing his memory regarding the position of the various structures he is about to encounter". Harvey Cushing, in his Macewen Memorial Lecture of 1927, paid homage to Macewen's monograph on pyogenic diseases of the brain and spinal cord as a landmark in surgery of the nervous system. It was also one of the first medical books that Cushing purchased. Osler pointed out, "a most important, one might almost say essential factor in the successful treatment of intracranial suppuration is an intelligent knowledge on the part of the surgeon of the work and works of William Macewen". ${ }^{30,32}$
Macewen's Work with Endotracheal Intubation (ET) and Anesthesia ${ }^{33}$

In 1870, as the medical superintendent of the Belvidere Fever Hospital in Glasgow, Macewen began his work on intubation of the larynx as an alternative to tracheotomy in diphtheria, a pressing problem at the time in Glasgow. Even though O'Dwyer was often mentioned as the inventor of this technique, Macewen described and practiced it a decade earlier. Incredibly, Macewen practiced inserting rubber or gum elastic catheters on himself! Macewen's contribution also included the ability to seal off the air around the ET tube by packing, probably a first description of the kind. He laid down rules and guidance for intubation of the larynx and wrote the definitive article in Heath's Dictionary of Practical Surgery.

\section{Thoracic Surgery}

Macewen had the distinction of performing the first pneumonectomy for tuberculosis in 1895 , followed by a thoracoplasty on the patient 4 weeks later. The patient was well after 11 years. ${ }^{34}$

\section{Orthopedics}

Macewen was an orthopedic surgeon long before that term was used. He did pioneering work in the transplantation of bone and osteotomy. ${ }^{34}$ He once transplanted a part of the tibia into the humerus of another patient. Subsequent operations demonstrated strong new bone formation. His special interest was in the correction of the sequelae of rickets, which was a common problem at that time. He published a monograph on knock-knee, bow-leg, and other deformities. His intense interest in orthopedics continued throughout his career. In 1916, he helped to found the Princess Louise Scottish Hospital for Limbless Sailors and Soldiers at Erskine (now the Erskine Hospital), near Glasgow, an urgently needed facility for the thousands of servicemen who lost limbs in the First World War. Macewen was its first surgeon and with the help of engineers and workers of the nearby shipyards, designed the Erskine artificial limb. He trained a team of patternmakers to manufacture them for the hospital. ${ }^{28-30}$

Macewen received many honors and distinctions during the course of his career. He was made a Fellow of the Royal Society in 1895 and President of the British Medical Association in 1922. He was knighted in 1902. Many international recognitions followed, including honorary membership of the Imperial Academy of St Petersburg, Rome, American Surgical Society, and a corresponding member of the Surgical Society of Paris. Macewen died in Garrochty, Isle of Bute, on March 22, 1924. ${ }^{27-30}$

\section{Curious Anecdote}

In 1889, Macewen was invited to become the first Professor of Surgery at the newly established Johns Hopkins Medical School with a promise of total authority over the department except the supervision and training of the nursing staff. He refused ${ }^{29}$

\section{Ogilvie, Sir William Heneage (1887-1971) (Figs 8 and 9) ${ }^{35-40}$}

William Heneage Ogilvie (Fig. 8) was born in Valparaiso, Chile on July 14,1887 , to a Scottish engineer. He graduated from Clifton College and New College, Oxford with first-class honors in physiology in 1910. He qualified for MRCS LRCP in 1913 at Guy's Hospital in London. He became BM BCh Oxon in the same year.

Ogilvie served as a surgeon during the Balkan war of 1912 to 1913 as well as during both World Wars, one of the few surgeons to 
have served in three wars. ${ }^{35}$ He served as surgeon for emergency cases in a hospital in France from 1915 to 1917 and in the RAMC from 1917 to 1920. During World War II, he was a Consulting Surgeon East Africa Command from 1940 to 1942 . He was the Consulting Surgeon of Middle East Land Forces in 1942 to 1944, and of Eastern Command in 1944 to 1945 with the rank of Major General.

Ogilvie obtained his MD in 1924 and was on the staff of Guy's hospital in London for 23 years. He was famous for his teaching and expertise in problems of gastric surgery and rapidly built up a successful practice. He attracted a galaxy of visitors from surgical centers all over the world.

Ogilvie served with distinction in many offices in the Royal College of Surgeons. He was Vice-President from 1945 to $1947,{ }^{40}$ delivering the distinguished Bradshaw Lecture on "Surgical handicraft" in 1947, an inspiring and impressive oration. He was elected Hunterian Professor in 1924 and later became a member of the Court of Examiners. A member of many other professional bodies, he received honorary fellowships from American College of Surgeons, Royal College of Surgeons, Canada and Australasia. He was awarded the KBE (Knight Commander of the Most Excellent Order of the British Empire) in 1946. ${ }^{35,40}$

Ogilvie was famous for his insistence on the performance of a colostomy for all wounds of the colon and argued thus: "....others

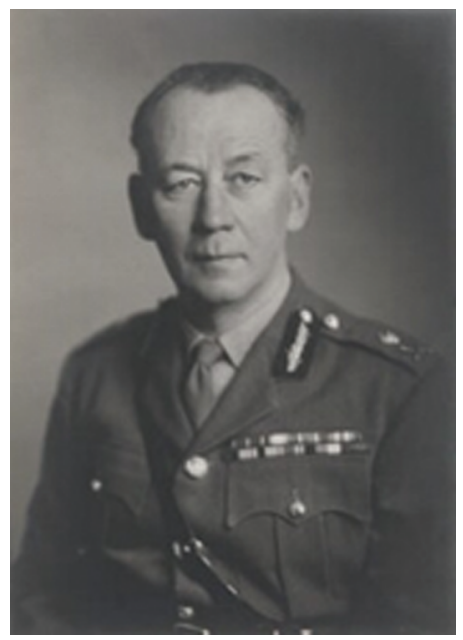

Fig. 8: William Henegae Ogilvie have died who would still be alive had they fallen into the hands of a surgeon with less optimism and more sense". ${ }^{36}$ The eponymous syndrome of Ogilvie described two cases of colonic ileus that he attributed to sympathetic deprivation caused by invasion by tumor. ${ }^{36}$ Relevant to the "open abdomen", 37,38 he was the first one to recognize its benefits. As far back as 1945, he described in Lancet the use of a "double sheet of light canvas or stout cotton cut rather smaller than the defect in the muscles and sutured into place with interrupted catgut sutures" for a temporary closure of abdominal war wounds when there was too much tension to close primarily. He proceeded to describe the use of Vaseline-impregnated gauze rolls overexposed viscera and closure of wound over them with strips of Elastoplast ${ }^{\circledR}$ or stitches. In a subsequent report in 1945 , Ogilvie advocated the same technique to leave the abdomen open and close it secondarily after 1-4 days. He described it as akin to draining an abscess by open drainage $!^{39}$ In a lecture given at the British Postgraduate Medical School, Hammersmith, Ogilvie commented: ${ }^{37}$ "Another generalization I would make is that, while many people would call this a plaster war, it will in the end be truer to call it a Vaseline war. The more we use Vaseline, the more we come to trust it, and the wider do we find its uses. If the soldier had to confine himself to one chemical product, it might well be vaseline which' can lubricate his rifle, soften his boots, smarten his on parade, cure his constipation, and, if need be, his wounds".

The open abdomen is a remarkable contribution. Even though the concept was forgotten for many centuries, the immense benefit this offers to critically injured and ill patients is now increasingly recognized. ${ }^{2,38}$

Ogilvie was a prolific writer. He authored nearly 200 articles in medical journals and was the joint editor of The Practitioner from 1946 to 1962 and editor of the first two editions of Recent Advances in surgery. He was well known for his original observations and aphorisms and as an essayist. Some notable examples ${ }^{35,39}$ Surgery, orthodox and heterodox (1948), No miracles among friends (1959) and the tired businessman (1964), all thought-provoking and inspiring. Some of Ogilvie's quotable opinions: "Organization is no substitute for genius. No amount of bureaucracy could have discovered Penicillin". "A misleading symptom is misleading only to one able to be misled". "The surgeon who is his own physician, though he often has a fool for a colleague, has the happiness of working in an atmosphere of mutual confidence and admiration".
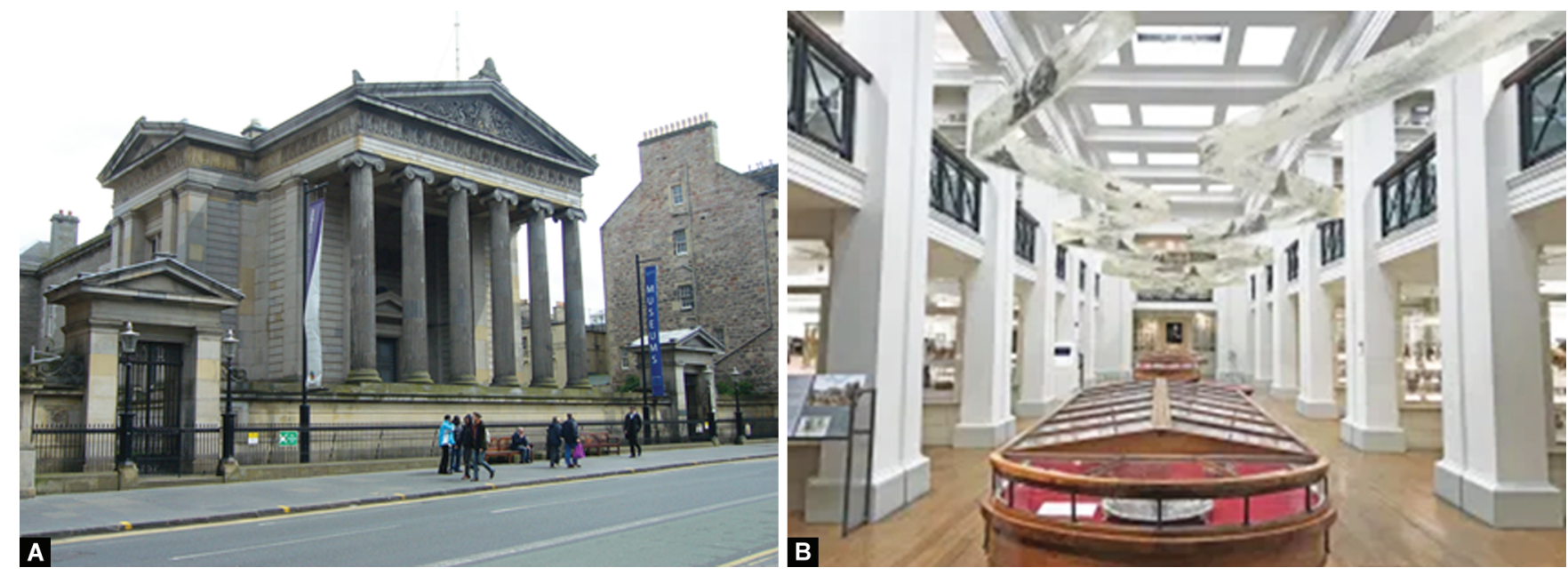

Figs 9A and B: Surgeons' Hall Museums, Edinburgh 
Ogilvie had other hobbies he was passionate about: travel and yachting. He founded the Surgical Travelers Club of a small and select group of colleagues to visit surgical centers in the British Isles and Europe. He was also an ardent sailor and presided over several societies of sailors. ${ }^{40}$

Ogilvie died on April 15, 1971. The British Medical Journal gave this handsome tribute in his obituary: "...a curious mixture of shrewdness and ingenuousness. There was always something of the innocence and wonder of a child about him, and it was this trait in his character that made him so sensitive to the inevitable blows of life". ${ }^{40}$

\section{Miscellaneous Pioneers}

Many other great Scots of anatomy and surgery deserve at least a passing mention. ${ }^{41}$

Robert Liston (1794-1847) ${ }^{41}$ was called "The Fastest Knife in the West End". With exclamations of "time me gentlemen", he would finish the above-the-knee amputation in $<30$ seconds. He also had the dubious reputation of a $300 \%$ mortality (the patient, the assistant who lost a finger, and a bystander who died from shock from nearly being sliced by his errant scalpel). Liston's aseptic practices (washing hands before surgery, donning a clean apron, using clean sponges, etc.) predated Pasteur and Simmelweis by half a century. He performed Europe's first operation under anesthesia. He introduced several new concepts in amputations, artery forceps that lock to stop bleeding, a long leg splint for immobilization of femoral fractures, a mirror to visualize the larynx, and a special clamp for bones. He was the first surgeon in England to excise the scapula [5] and do a maxillectomy. He was a great anatomist and teacher. Liston died in 1847 at age 53 of a ruptured aortic aneurysm. For nearly 100 years following his death, the Liston Medal for Surgery was awarded for surgical excellence at University College Hospital.

Thomas Annandale (1877-1907) ${ }^{41}$ performed the first repair of the meniscus and the first successful removal of an acoustic neuroma. He also introduced the pre-peritoneal approach to inguinal hernia repair.

Henry Hill Hickman (1800-1830) ${ }^{41}$ was considered one of the "fathers of anesthesia".

George Kellie (1770-1829) ${ }^{41}$ described the Monro-Kellie doctrine on intracranial pressure.

James Rutherford Morison (1853-1939) ${ }^{41}$ described Morison's pouch.

James Hogarth Pringle (1863-1941) ${ }^{41}$ described the Pringle maneuver for occluding the portal triad to control hemorrhage. Also the first surgeon in Britain to carry out a saphenous vein graft. He pioneered the hindquarter amputation.

Harold Stiles (1863-1946): ${ }^{41}$ the first surgeon to transplant the ureter into the sigmoid colon; the first to perform the first pyloromyotomy for congenital hypertrophic pyloric stenosis. Ramstedt often is credited for this. Also known for research in tuberculosis and breast cancer.

\section{SUMMARY}

As exhibited magnificently in the Surgeons' Hall Museums, ${ }^{3}$ the Royal College of Surgeons of Edinburgh, established in 1505 as the Barber Surgeons of Edinburgh was one of the oldest medical organizations in the world and was the phrontistery for these brilliant surgeons and anatomists. Edinburgh and Scotland in the 18th and 19th centuries were renowned for their cutting-edge medicine and surgery.

\section{ACKNOWLedgment}

The author gratefully acknowledges Professor Sunil K Pandya for his review of the manuscript and valuable suggestions.

\section{References}

1. Ogilvie WH. Surgical lessons of war applied to civil practice. Br Med J 1945;1(4400):619-623. DOI: 10.1136/bmj.1.4400.619.

2. Ivatury R. Open abdomen: historical notes. In: Open abdomen: A comprehensive practical manual Coccolini F, Ivatury R, Sugrue $M$, et al., ed. Springer; 2018. pp. 1-26.

3. https://www.sciencehistory.org/distillations/magazine/auldmedicine. Accessed March 17, 2021.

4. Dingwall HM. A history of scottish medicine: themes and influences. Edinburgh: Edinburgh University Press; 2002. p. 108. ISBN 0-74860865-6.

5. Macintyre I, Munro A. The Monros - three medical dynasties with a common origin. JR Coll Physicians Edinb 2015;45(1):67-75. DOI: 10.4997/JRCPE.2015.116.

6. Pearce JM, The Monros: a medical dynasty https://hekint. org/2018/06/26/ accessed Jan 18, 2021.

7. Rennie D. Editorial peer review: its development and rationale. In: BMJ Jefferson EG, ed., London: Peer Review in Health Sciences; 1999. pp. 1-13.

8. Guerrini A. Alexander monro primus (1697-1767). In: Oxford Dictionary of National Biography. Oxford: Oxford University Press; 2004. p. 18964.

9. Rosner L. Alexander monro secundus (1733-1817). In: Oxford Dictionary of National Biography. Oxford: Oxford University Press; 2004. p. 18965.

10. Macintyre IMC. Scientific surgeon of the enlightenment or 'plagiarist in everything': a reappraisal of Benjamin bell (1749-1806). R Coll Physicians Edinb 2011;41(2):174-181. DOI: 10.4997/JRCPE.2011.211.

11. Bell B. A treatise on gonorrhea virulenta, and lues venerea. 2 volumes, Edinburgh: James Watson and Co. [etc.]; 1793.

12. Ellis $\mathrm{H}$, Abdalla S. A history of surgery. 3rd ed., CRC Press; 2018. p. 61.

13. Goddard J. The knife man: The extraordinary life and times of John Hunter, father of modern surgery. J Royal Soc Med 2005;98(7):335. DOI: 10.1258/jrsm.98.7.335.

14. Ellis H, Abdalla S. A history of surgery. 3rd ed., CRC Press; 2018. pp. 57-61.63-4.

15. Kapp KA, Talboy GE, John Hunter, father of scientific surgery. Bulletin of the Surgical History Group, Papers from the 2017 Poster Competition, CLINICAL CONGRESS 2017 | SAN DIEGO, CA pp 34-41.

16. 'Nova and Vetera. The Napoleon of Surgery. British Medical Journal, 1954;151. Jan 16.

17. Graham JM, Syme J. Br J Plast Surg 1954;7:1-12.

18. Royal College of Surgeons. Plarr's Lives of the Fellows. Syme James. 2013: April 10.

19. Literary Notes. Br Med J 1908;1(2461):514. DOI: 10.1136/bmj.1.2461.514.

20. Syme J. Illustrations of the antiseptic principle of treatment in surgery. Br Med J 1868;1(366):1. DOI: 10.1136/bmj.1.366.1.

21. Ellis H, Abdalla S. A History of Surgery. 3rd ed., CRC Press; 2018. pp. 72-73. 159.

22. Pitt $D$, Aubin J-M. Joseph Lister: father of modern surgery. Canad J Surg 2012;55(5):E8-E9. DOI: 10.1503/cjs.007112.ISSN 0008-428X.

23. Lister J, "(1827-1912)". Plarr's Lives of the Fellows. The Royal College of Surgeons of England. Retrieved 1 August 2020.

24. Clark PF. "Joseph Lister, his Life and Work". The scientific monthly. Am Assoc Adv Sci 1920;11(6):518-539. Bibcode: 1920 Sci Mo. 11.518C. 
25. Bonnin JG, Le Fanu WR. "Jospeph Lister 1827-1912".J Bone Joint Surg London 1967;49(1):4-23.

26. Ellis H, Abdalla S. A history of surgery. 3rd ed., CRC Press;; 2018. pp. 86-91. 153-155.

27. Joseph L, The Royal College of Surgeons of England Bulletin, Saints and Sinners: 10.1308/147363512X13189526440393.

28. Bowman AK. The life and teaching of sir William Macewen. A chapter in the history of surgery. Regional Medical Officer to the Department of Health for Scotland, 9\# x 6 in, London, Edinburgh, Glasgow 1942. pp. $425+x i i$.

29. Cano AV. A sketch of Sir William Macewen. Br J Surg 1967;54:1-7.

30. Obituary. Sir William Macewen. Br Med J 1924.603-608.

31. Summerly P. Sir William Macewen (1848-1924): surgeon and clinical photographer. Scott Med J 2007;52(4):44-46. DOI: 10.1258/ rsmsmj.52.4.44.

32. Canale DJ. William Macewen and the treatment of brain abscesses: revisited after one hundred years. J Neurosurg 1996;;84(1):133-142. DOI: 10.3171/jns.1996.84.1.0133.
33. Macewen W. Introduction of tracheal tubes by the mouth instead o f performing tracheotomy or laryngotomy. Br Med J 1880;2(122124):163-165. DOI: 10.1136/bmj.2.1022.163.

34. Ellis H, Abdalla S. A history of surgery. 3rd ed., CRC Press; 2018. p. 161.

35. The Royal College of Surgeons of England. "Lives of the Fellows". 2014-09-22. Ogilvie, Sir William Heneage (1887-1971).

36. OgilvieH.William Heneage Ogilvie. Dis Colon Rectum 1987;30(12):984987. DOI: $10.1007 /$ BF02554291.

37. Ogilvie WH. The late complications of abdominal war wounds. Lancet 1940;236(6105):253-257. DOI: 10.1016/S0140-6736(01)08769-4.

38. Quoted in: Kreis BE, Otterloo JCA, Kreis EW. Open abdomen management: a review of its history and a proposed management algorithm. Med Sci Monit 2013;19:524-533. DOI: 10.12659/ MSM.883966.

39. Ogilvie's quotations. http://surgstudent.org/lectures/famous/ node43.html accessed March 17, 2021.

40. Obituaries. Br Med J 1971. 282.

41. https://en.wikipedia.org/wiki/List_of_University_of_Edinburgh_ medical_people accessed March 17, 2021. 